\title{
Perception of a chronic volcanic hazard: persistent degassing at Masaya volcano, Nicaragua
}

\author{
Saskia M van Manen
}

\begin{abstract}
This study takes a combined qualitative and quantitative approach to examining the chronic hazard posed by persistent degassing at Masaya volcano, Nicaragua. The gas is a highly salient threat in communities surrounding Masaya volcano, with the elevated salience level of his invisible hazard deriving from the highly perceptible impacts of the degassing; these include individual and material impacts such as increased prevalence of self-reported respiratory disease and decreased crop diversification and productivity. Qualitative results concur with findings from a quantitative assessment of ambient $\mathrm{SO}_{2}$ exposure using diffusion tubes: the current level of $\mathrm{SO}_{2}$ degassing far exceeds international guideline values, making it a likely cause of adverse health effects for the general population. Conversely contaminant levels of heavy and toxic metals in foodstuffs were found to be below international standards. A community-based integrated hazard mitigation approach identified by this research is the cultivation of crops, particularly pineapple (Ananas comosus) and pitaya (Hylocereus sp.), that are better able to withstand the local environmental conditions (e.g. increased atmospheric $\mathrm{SO}_{2}$ and acid gas deposition). Despite this, little is known regarding disaster response and risk reduction at the community level and the gas hazard is largely overlooked. This shows large scope for increasing resilience in collaboration with the community, through for example the development of community-level risk management committees, improvement and implementation of (gas) mitigation strategies and disaster preparedness approaches. By reducing the impacts of the chronic hazard posed by persistent volcanic degassing, resilience to acute hazards is also likely to improve.
\end{abstract}

Keywords: $\mathrm{SO}_{2}$; Hazard; Exposure; Disaster risk management; Mitigation

\section{Introduction}

Inter- or cross-disciplinary studies in volcanic areas are becoming more commonplace as ways of improving disaster risk reduction are sought (e.g. Gregg et al. 2004; Ricci et al. 2013; Donovan 2010; Gaillard 2008; Haynes et al. 2008). The vast majority of these studies focus on explosive and/ or acute volcanic hazards, however, chronic hazards, such as those posed by continued long-term exposure to the primary volcanic gases, such as sulphur dioxide $\left(\mathrm{SO}_{2}\right)$, hydrogen sulphide $\left(\mathrm{H}_{2} \mathrm{~S}\right)$, hydrogen chloride $(\mathrm{HCl})$ and hydrogen fluoride (HF), can result in a range of chronic ailments (e.g. Longo et al. 2010; Baxter et al. 1982; Hansell and Oppenheimer 2004), reduced agricultural productivity, and acidification of rain and groundwater that contaminates

Correspondence: saskia.vanmanen@open.ac.uk

Environment, Earth and Ecosystems, The Open University, MK7 6AA Milton Keynes, UK water supplies (e.g. Delmelle et al. 2002). In addition, indirect effects are thought to impede development and poverty reduction efforts (DFID 2006), contributing to the (economic) cost of low-level chronic hazards.

A prime example of a persistently degassing volcano is Masaya, Nicaragua (Figure 1), which has been almost continuously active since the mid $16^{\text {th }}$ century (Viramonte and Incer-Barquero 2008). Studies have shown that the locality regularly exceeds WHO air quality standards with regards to atmospheric $\mathrm{SO}_{2}$ concentrations (e.g. Delmelle et al. 2002; Stoiber et al. 1986; Baxter et al. 1982). As persistent volcanic degassing is not considered a primary volcanic hazard, it is frequently overlooked in terms of disaster preparedness (D’Alessandro 2006). However, it can be argued that based on its diffuse but wide-ranging impacts as listed in the previous paragraph, this chronic hazard is equally as important as acute hazards. Therefore

\section{Springer}




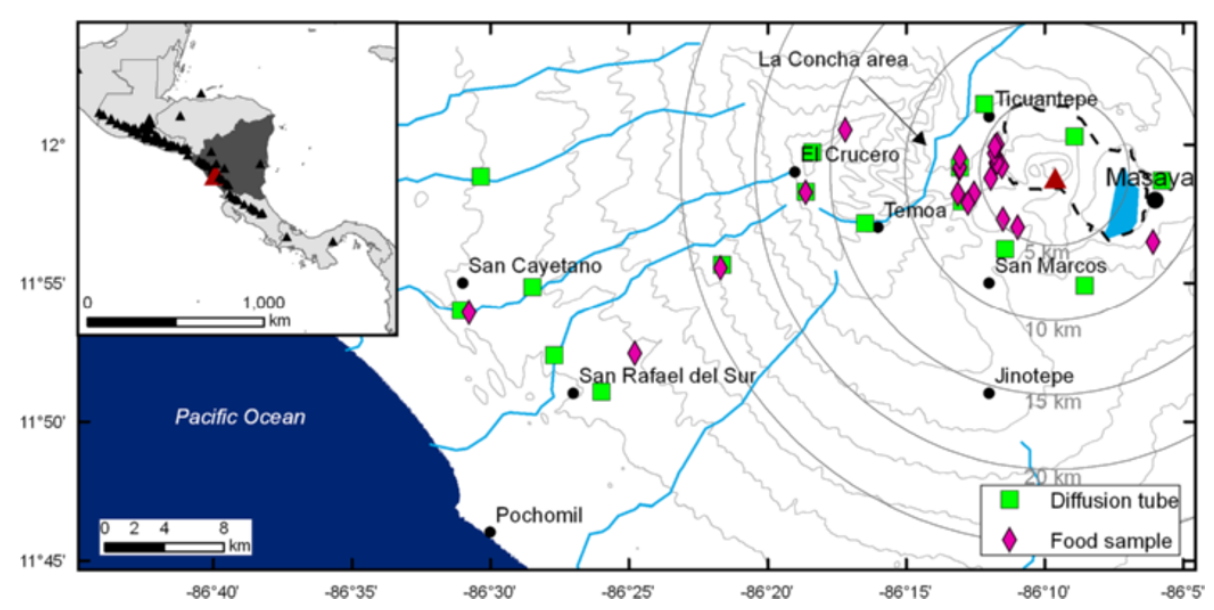

Figure 1 Location figure. Inset shows location with respect to Central America and the Central American Quaternary volcanic chain (volcano locations from the Smithsonian Global Volcanism Program and Country boundaries from DIVA-GIS). Dashed line shows the caldera boundary, which is also the limit of the National Park. A selection of localities mentioned in the text is shown. Concentric circles indicate distances from the active vent in $5 \mathrm{~km}$ intervals. Green squares represent sites of diffusion tubes and pink diamonds are crop sampling locations. Elevation contour data based on ASTER GDEM, a product of METI and NASA.

mitigation strategies, here defined as 'The lessening or limitation of the adverse impacts of hazards and related disasters' (UNISDR 2009), should be considered. Policy and legislation are essential components of risk reduction strategies, but it has been found that the most successful results are achieved through community involvement and work at the local level (e.g. Cronin et al. 2004; UNDP 2004; Mercer et al. 2010; Kelman and Mather 2008).

The aim of this study was to evaluate the chronic gas hazard at Masaya from a predominantly qualitative perspective, as peoples' response to hazards and risk ('The combination of the probability of an event and its negative consequences' (UNISDR 2009) is proportional to their understanding and awareness. A limited quantitative investigation was also undertaken to provide context for the qualitative findings. Specific objectives of the study included (i) examining the level of awareness with respect to the hazards posed by the persistent degassing and how this related to the area affected (ii) documenting the perceived impacts of the volcanic activity and (iii) exploring if and how hazard perception in the area has affected individual and community-level hazard and risk management.

\section{Setting}

Masaya is a basaltic shield volcano situated $20-25 \mathrm{~km}$ southeast of Nicaragua's capital city Managua. Masaya is capable of Plinian activity and has experienced at least four caldera forming eruptions (Williams 1983). The caldera is approximately $11.5-6 \mathrm{~km}$ wide with its long axis oriented NW-SE, parallel to the Central American Quaternary volcanic chain. The active Masaya Volcanic Complex, approximately $3.5 \mathrm{~km}$ in diameter, lies within this and is composed of a number of collapse craters. In 1979 the main area of the volcanic complex was declared Nicaragua's first national park (Parque Nacional Volcán Masaya). The park is operated and maintained by the national park service (Servicio de Parques Nacionales), part of the Ministry of Environment and Natural Resources (MARENA; Ministerio del Ambiente y los Recursos Naturales).

Owing to its persistent activity Masaya features frequently in local folklore and historical accounts (Viramonte and Incer-Barquero 2008). Autochthonous people believed Masaya was a god and made frequent offerings and human sacrifices (Viramonte and Incer-Barquero 2008). In 1524 its activity, which included a lava lake, was first described by the Spaniards and subsequently it was mentioned in copious post-Columbian reports, frequently referred to as "The mouth of Hell" (Viramonte and IncerBarquero 2008). During the last recorded effusive event in 1772 (McBirney 1956) the bishop of Granada carried the image of Christ of Nindiri in a procession and faced the incoming lava flow in order to stop it. Coincidentally the eruption ceased afterwards (Viramonte and IncerBarquero 2008).

Current activity is constrained to the Santiago crater which was formed between 1850-1853 (Viramonte and Incer-Barquero 2008). Activity takes the form of continuous degassing and small vent clearing explosions and is monitored by INETER (Instituto Nicaragüense de Estudios Territoriales; http://www.ineter.gob.ni). The degassing is characterised by annual to decadal cycles (Rymer et al. 1998), with at least five cycles recognised since formation (Stoiber et al. 1986) and repose intervals of 3-5 years (SINAPRED 2005). Between 1972 and 2007 an average of approximately 1100 metric tonnes of $\mathrm{SO}_{2}$ were emitted 
per day (Nadeau and Williams-Jones 2009 and references therein). There was significant $\mathrm{SO}_{2}$ release from the Santiago crater in 1981 (SINAPRED 2005) and there has been significant gas discharge since 1999, which has caused extensive environmental contamination of the area (Delmelle et al. 2001; Delmelle et al. 2002; Parnell 1986; SINAPRED 2005). The most recent vent clearing explosions were recorded between 30 April 30 and 3 May 2012 (INETER 2012), after this research was conducted. Prior to the work presented here, the most recent minor explosive activity occurred on June 182008 (INETER 2008) when an explosion discharged moderate quantities of volcanic ash. On April 232001 an explosion at the summit crater of Masaya produced fragments of up to $60 \mathrm{~cm}$ in diameter that travelled as far as $500 \mathrm{~m}$ from the vent (Smithsonian Institution 2001). Although no one was killed or severely injured during this event, there were numerous tourists present around the crater and a number of vehicles in the Santiago crater parking lot (Oviedo Plaza) were damaged. Ashfall and dangerous concentrations of volcanic gases were reported in Ticuantepe, $6 \mathrm{~km}$ NW of Masaya Smithsonian Institution (2001).

National- and departmental-level hazard response plans and hazard maps can be downloaded from SINAPRED (Sistema Nacional para la Prevencion, Mitigacion y Atencion de Desastres; www.sinapred.gob.ni) and show that the area around Masaya is at risk of flooding, landslides, earthquakes and volcanic hazards (e.g. SINAPRED 2005, 2009). The volcanic hazard assessment at Masaya as presented in the 2005 SINAPRED report, prepared in collaboration with INETER and the World Institute for Disaster Risk Management, states that lava flows are thought to be able to travel up to $10 \mathrm{~km}$ (first mentioned by Williams (1983) based on prehistorical lava flows), pyroclastic flows up to $20 \mathrm{~km}$, ejecta up to $1 \mathrm{~km}$ and ashfall is predicted to go 1-25 km west. Although lava flows are most likely to be contained within the caldera that encompasses the National Park, they would still present a hazard to the tourism infrastructure and illegal settlements present within the Park. The biggest threat related to the gases is reported to be the potential for larger explosions, which has been assigned a high threat level, due to pressurisation of the system if vents become blocked (SINAPRED 2005). Secondary threats are impacts of acid rain on (human) health, vegetation and metal hardware, which have been assigned medium threat levels. The town of Masaya itself is considered to be at low-moderate risk of these gases due to the dominance of west blowing trade winds. Conversely, areas west of the crater are at high risk of the gases (SINAPRED 2009; AMUNIC, AMUSCLAM 2010).

\section{Methods}

\section{Qualitative data collection}

Semi-structured interviews were recorded using a handheld Olympus voice recorder in a wide variety of locations around Masaya volcano between 20 February and 14 March 2012. Semi-structured interviews pose the same core questions to each participant, but they provide the opportunity to seek clarification of responses and discussion of subjects (Ritchie and Lewis 2003), which are advantages over the use of questionnaires or structured interviews. These types of interviews seek out the participant's point of view to gain a range of insights on specific issues, rather than attempting to generalise behaviour across a population. Drawbacks of this technique include that a lot of additional non-relevant information may be gathered complicating data organisation and analysis (Mikkelsen 1995). For this study eleven interview questions were designed a priori to provide a framework and examine various aspects of interest: hazard salience, hazard knowledge, hazard and risk perception (Table 1). Care was taken to cover all the relevant topics while not making the list of questions too long, the latter to aid participation rate.

An accidental sampling technique (Bird 2009) with a spatial component was used to cover the majority of the

Table 1 Semi-structured interview questions

\begin{tabular}{ll}
\hline Question & Design reason \\
How long have you and your family lived in this area? & Socio-demographic \\
Tell me a little about your life. For example, what do you do on a typical day? & Salience \\
Where do you spend most of the day? & Collective memory \\
What are the main problems/hazards in your town? & Hazard and/or risk perception \\
Did your ancestors talk about Masaya volcano? If so, what did they say? & Hazard knowledge \\
How dangerous do you think Masaya volcano is? & Knowledge emergency plans \\
How can you tell if Masaya volcano could become dangerous? & Risk perception \\
What would you do if there were danger signs coming from Masaya volcano? & \\
Has the volcano had some effect or impact on you, your family or your community? & \\
\hline
\end{tabular}


villages around Masaya. This means that all individuals encountered during the study period were considered for inclusion, while a wide geographical area surrounding the volcano was covered. Generally one or two individuals in each village or town visited were interviewed, and interviews were conducted at the place the participant had been approached (e.g. in their garden, house or place of work). All participants were local residents, no other stakeholders were specifically interviewed as part of this work. Initial contact with participants was established by direct approach. To establish eligibility for participation ( $>18$ years old) in the study participants were asked their age if they appeared under 30. Prior to the interviews, potential participants were provided with a verbal explanation and introductory letter describing the nature of the research. The letter also contained the researcher's contact details to enable participants to withdraw from the interview at any point and retract their data without consequence during a specified time period after the interview had been conducted. None of the participants exerted this right. If participants agreed to take part in the research, consent for participation in the research and recording of the interview was always obtained verbally as Nicaragua has a relatively low literacy rate ( $78 \%$; http://data.worldbank. org/country/nicaragua). Once verbal consent was obtained, participants were asked to vocally repeat their consent while being recorded. To ensure confidentiality all data presented in this study have been anonymised. Ethical approval for the research was obtained from the Open University's Human Research Ethics Committee.

Due to time constraints transcription of the digital audio files was outsourced to a commercial company but translation, analysis and interpretation of the interview data were performed by the researcher. Transcripts were translated into English, however, frequent reference was made to the original Spanish texts and audio files to ensure the data were interpreted as they were intended. Data were coded using 'a priori' and 'grounded' codes using the software package NVivo 8. Coding of qualitative data is the process of identifying topics, themes and categories in the text. A priori codes are topics that have been established as relevant prior to the data collection, whereas grounded codes represent important subjects that have emerged from the text. Although there is much debate regarding the use and value of software in qualitative data analysis (e.g. Bergin 2011) NVivo 8 was used as it enables organisation, classification and sorting of qualitative data; as qualitative analysis is predominantly based on interpretation rather than analytics (e.g. Cassell and Symon 1994), using software just provides a systematic approach to data handling rather than answers. Mistakes were found in some of the transcriptions, these were mostly related to names or technical terms. Due to the researcher's familiarity with the subject and the area many of these could be rectified and are therefore not thought to affect the content analysis performed here. In the results, discussion and conclusion sections those sentences between quotation marks and in italics are direct (translated) quotes from participants. For clarity on the origin of the quotes, a number in brackets at the end of the quote identifies the individual participant and the name of the area, town or village where they were interviewed. The quotes have been included to illustrate examples, and clarify links between data, interpretation and conclusions as they provide a clearer understanding than paraphrasing by the author.

\section{Quantitative sampling}

Between 26 January 2012 and 15 February 2012 two-types of commercially available (Gradko) diffusion tubes of were used to examine (1) $\mathrm{SO}_{2}$ and (2) acid gas $(\mathrm{HCl}, \mathrm{HF}, \mathrm{HBr}$, and $\mathrm{HNO}_{3}$ ) concentrations around Masaya (Figure 1; Figure 2). The acid gas tubes also measured concentrations of $\mathrm{NO}_{2}$. Twenty-five tubes were exposed for durations between 10 and 26 days, with only one site being exposed less than the two weeks recommended and none of the sites exceeding the recommended maximum of 4 weeks (www.gradko.co.uk). Diffusion tubes provide an average integrated concentration value (in $\mu \mathrm{g} \mathrm{m}^{-3}$ ) for the length of time that the tube has been exposed, short-term variations are not recorded. Data have been blank corrected and inter-tube variability was recorded using two sets of twinned tubes (Table 2).

Twenty-nine crop samples were also obtained (Figure 1), these were predominantly banana (Musa sp.), plantain (Musa sp.), pineapple (Ananas comosus) and the root vegetable "quiquisque" (Xanthosoma sp.). Although pitaya (Hylocereus sp.) is widely cultivated in the area for the domestic and international market, only samples of the plant were obtained rather than the fruit as it was not in season during this fieldwork. Single specimens of mango (Mangifera sp.) and spinach (Spinacia oleracea) were also gathered. As a result of logistical constraints samples were cut to remove skin using a plastic knife and pieces of the edible flesh were subsequently air- and sun-dried while in the field, therefore wet and dry weights were not available. Dry samples were transported to the UK where a heavy metals analysis using ICP-MS was carried out by a commercial consultancy. Heavy and toxic metals ( $\mathrm{Al}, \mathrm{Cr}, \mathrm{Fe}$, $\mathrm{Co}, \mathrm{Ni}, \mathrm{Cu}, \mathrm{Zn}, \mathrm{As}, \mathrm{Se}, \mathrm{Cd}, \mathrm{Sn}, \mathrm{Hg}$ and $\mathrm{Pb}$ ) were chosen as these are known to adversely impact health and the environment when encountered in excessive quantities (e.g. WHO 2013) and volcanoes present a natural source, either through degassing or ash emissions. Samples of approximately $5.0 \mathrm{~g}$ were weighed into in a $60 \mathrm{ml}$ beaker and mixed with $5 \mathrm{ml} 68-71 \% \mathrm{~m} / \mathrm{m} \mathrm{HNO}_{3}$, left for 1 hour at room temperature and then heated to $60^{\circ} \mathrm{C}$ for 2 hours. Subsequently $3 \mathrm{ml}$ of $30 \% \mathrm{H}_{2} \mathrm{O}_{2}$ was added incrementally and the mixture was warmed to $60^{\circ} \mathrm{C}$ until a clear solution 

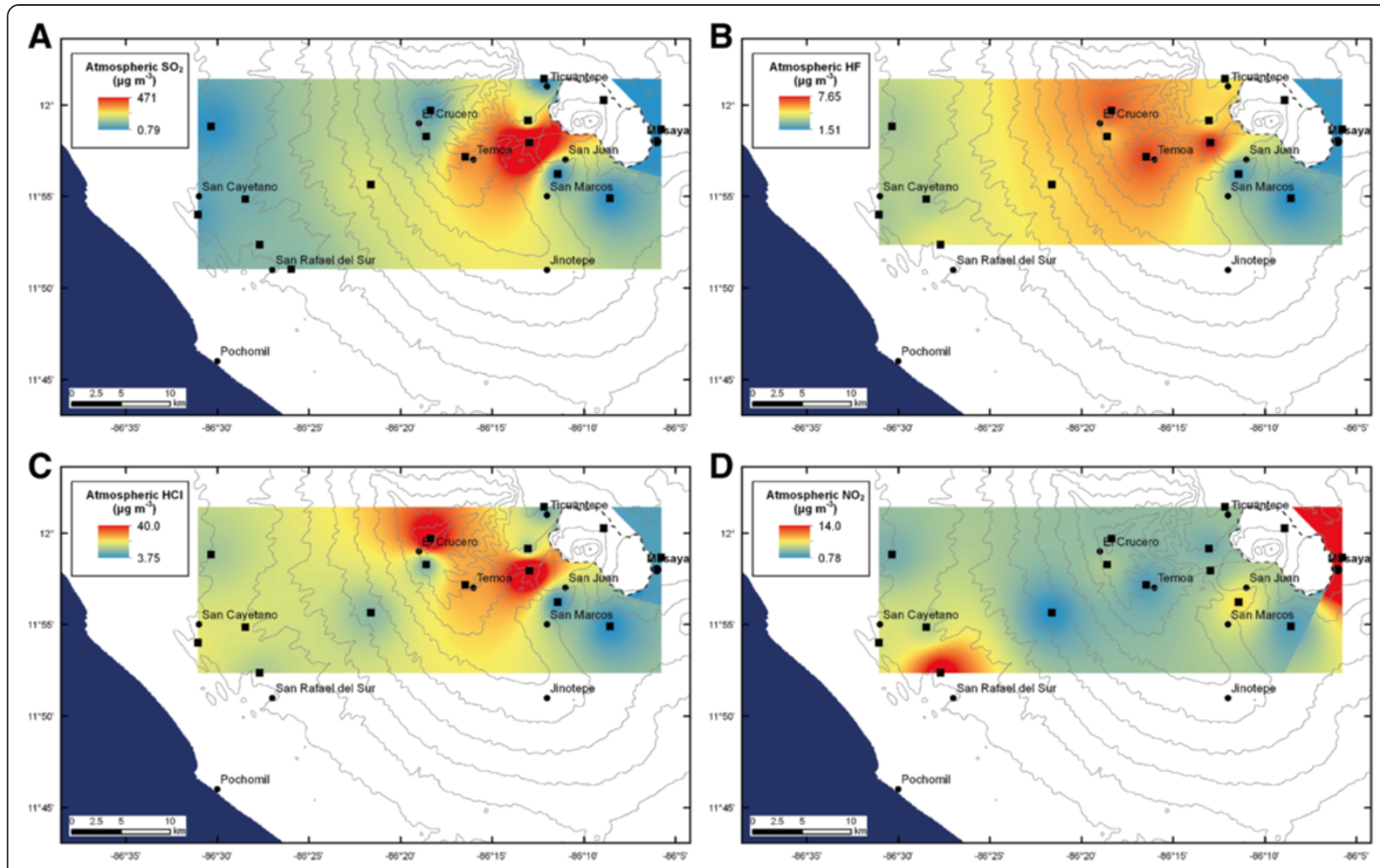

Figure 2 Ambient concentrations in $\mathbf{~ g ~ m ~}^{-3}$ of volcanogenic gases at Masaya as measured in February-March 2012. Surfaces interpolated from point measurements using IDW. (A) SO 2 concentrations at Masaya as measured in February-March 2012. Large areas downwind exceed the WHO guideline value of $20 \mathrm{mg} \mathrm{m}^{-3}$ per 24 hours. (B) $\mathrm{HCl}$ (C) $\mathrm{HF}$ and (D) $\mathrm{NO}_{2}$.

formed. After digestion the mixture was cooled to room temperature and made up to $50 \mathrm{ml}$ with deionised water. To convert concentrations back to fresh weight an average water content for each species was used (75\% banana; 65\% plantain; $87 \%$ for pineapple; potato water content, $79 \%$, was used for quiquisque (USDA 2012); and 96\% pitaya plant (Jaafar et al. 2009).

Ambient gas exposure guidelines and maximum levels of contaminants in foodstuffs vary across countries and organisations but in this work World Health Organisation (WHO) and UK guidelines have been used when Nicaraguan limits were not available. Exposure limits also change, for example the 2005 updated version of the WHO's guidelines on $\mathrm{SO}_{2}$ stated that an annual exposure limit was no longer required as low annual levels are implied by compliance with the 24 hour limit.

\section{Results}

To provide context for the qualitative results, the quantitative findings are presented first. Diffusion tube data from 2012 (Figure 2; Table 3), interpolated using inverse distance weighting (IDW) with a spatial barrier as no data were collected inside the National Park, show that large areas downwind of the Masaya caldera, covering three administrative departments (Managua, Masaya and Carazo) and numerous municipalities (e.g. Ticuantepe, El Crucero, Masaya, La Concepcion, San Marcos) therein, exceed Nicaraguan and WHO exposure guidelines with regards

Table 2 Diffusion tube detection limit, inter-tube variability and blank concentrations

\begin{tabular}{lllll}
\hline Gas & Limit of detection $(\boldsymbol{\mu g})$ & Inter-tube variability $(\mathbf{\pm} \boldsymbol{\mu g})$ & Lab blank concentration $(\boldsymbol{\mu g})$ & Travel blank concentration $(\boldsymbol{\mu g})$ \\
\hline $\mathrm{SO}_{2}$ & 0.030 & 0.05 & 0.02 & $0.04,0.06$ \\
$\mathrm{NO}_{2}$ & 0.013 & 0.06 & 0.02 & $0.04,0.04$ \\
$\mathrm{HCl}$ & 0.157 & 0.05 & 0.04 & $0.42,0.35$ \\
$\mathrm{HF}$ & 0.017 & 0.01 & 0.01 & $0.15,0.14$ \\
$\mathrm{HBr}$ & 0.068 & $\mathrm{ND}$ & 0.05 & $0.05,0.04$ \\
\hline
\end{tabular}

These results indicate minimal contamination of the tubes, particularly when compared with the measured values obtained. ND $=$ Not Detected. If travel blanks were high, as with $\mathrm{HCl}$ and $\mathrm{HF}$, the lab blank was used to blank correct the data. 
to $\mathrm{SO}_{2}$. This was not the case for $\mathrm{HCl}, \mathrm{HF}$ or $\mathrm{HBr} . \mathrm{HCl}$ and $\mathrm{HF}$ are elevated in similar areas to $\mathrm{SO}_{2}$ and also decrease with distance from the vent. $\mathrm{HNO}_{3}$ was also only recorded at a single location where measured concentrations of $\mathrm{SO}_{2}, \mathrm{HCl}$ and $\mathrm{HF}$ were at their maximum levels. $\mathrm{NO}_{2}$ (Figure 2D) shows a pattern not consistent with that shown by the volcanogenic gases, instead it is elevated in urban and industrialised areas implying anthropogenic sources. $\mathrm{HBr}$ was only found at a single site at $35 \mathrm{~km}$ from the vent, at a location also exhibiting elevated levels of $\mathrm{NO}_{2}$, again suggesting an anthropogenic source.

Results of the food sample analysis (dry weight) are shown in Table 4. Extrapolating dry weight concentrations to fresh weight (Figure 3) showed that on average concentrations of heavy metals are greater in pineapples than in plantain, banana or quiquisque. Estimating total daily intake at $0.014,0.015,0.011,0.001$ and $0.038 \mathrm{~kg}$ for banana, plantain, pineapple, quiquisque and mango respectively (FAO 2007; CATIE 1996; SAGARPA 2005) and using $70 \mathrm{~kg}$ for an adult weight and $20 \mathrm{~kg}$ for a child it was found that none of the concentrations measured exceed guidelines published in the Codex Alimentarius (WHO and FAO 1995).

\section{The perceived hazards}

In February and March 2012, 37 semi-structured interviews were conducted with people living around Masaya volcano. A breakdown of basic demographics can be found in Figure 4. Depending on the participant it was found that there was not always a balance between the nature of the semi-structured interview and the length of the responses, with those more affected by the volcanic activity frequently providing more extensive and diverse accounts. Unfortunately high winds, common to the area, rendered parts of the interviews inaudible. The data from the interviews can be categorized into three broad themes: (i) (spatio-temporal) hazard awareness, (ii) physical and material impacts and (iii) mitigation and response. Figure 5 provides a summary of the findings presented below.

\section{Hazard awareness}

"For me the volcano always erupts, [it's] always active. [10, La Concha area]"

In the 37 interviews conducted the volcano was acknowledged as a hazard in 35 of them, the remaining 2 explicitly stated that they do not think the volcano is dangerous. Knowledge of hazards in the area derives from personal experience or collective memory, with Masaya also featuring in local folklore, "The volcano erupted March 16, 1762 (...). My mother told me that during the eruption the people of Nindiri and Masaya carried an image in procession. In Nindiri the Lord of Miracles was taken down to the beach and the population put their faith in his image to stop the lava. They also brought the Blessed Virgin Mary to the beach. They say the lava came to where he was, and burnt a finger of the image. (...) My mother also told me that her grandparents told her that their parents told them it was an eruption of a river of lava, which we know as a Hawaiian-style eruption (...). Today in Nindiri, (...) the tradition is maintained. On March 16 Lord of the Miracles is taken from the church down to part of the lagoon to commemorate this story [5, Masatepe]".

The main hazard mentioned, by 22 of the 37 participants, is the volcanic gas, recognised as a source of environmental pollution. However, two participants also view the degassing as reassuring as "There is no danger

Table 3 Gas exposure guidelines and maximum values found at Masaya

\begin{tabular}{|c|c|c|c|c|c|}
\hline \multirow{2}{*}{ Gas } & \multicolumn{2}{|c|}{ Exposure guidelines $\left(\mu \mathrm{g} \mathrm{m}^{-3}\right)$} & \multirow[t]{2}{*}{ Source } & \multirow{2}{*}{$\begin{array}{l}\text { Maximum recorded } \\
\text { concentration }\left(\mu \mathrm{g} \mathrm{m}^{-3}\right)\end{array}$} & \multirow{2}{*}{$\begin{array}{l}\text { Distance from } \\
\text { vent }(\mathrm{km})\end{array}$} \\
\hline & Time & Limit & & & \\
\hline \multirow{5}{*}{$\mathrm{SO}_{2}$} & 10 minutes & 500 & $\mathrm{WHO}^{\mathrm{a}}$ & \multirow{5}{*}{471} & \multirow{5}{*}{6.34} \\
\hline & 24 hours & 20 & & & \\
\hline & \multirow{3}{*}{ Annual } & 365 & Nicaraguab & & \\
\hline & & 50 & WHOc & & \\
\hline & & 80 & Nicaragua & & \\
\hline $\mathrm{HCl}$ & 1 hour & 750 & $U K^{d}$ & 40.0 & 6.34 \\
\hline \multirow[t]{2}{*}{ HF } & Monthly & 160 & $U^{e}$ & \multirow[t]{2}{*}{7.65} & \multirow[t]{2}{*}{6.34} \\
\hline & 1 hour & 200 & $\mathrm{WHO}$ & & \\
\hline \multirow{3}{*}{$\mathrm{NO}_{2}$} & \multirow{3}{*}{ Annual } & 400 & Nicaragua ${ }^{b}$ & \multirow{3}{*}{14.0} & \multirow{3}{*}{7.12} \\
\hline & & 40 & $\mathrm{WHO}^{\mathrm{a}}$ & & \\
\hline & & 100 & Nicaraguab & & \\
\hline $\mathrm{HBr}$ & 1 hour & 700 & $U K^{e}$ & 4.13 & 35.0 \\
\hline
\end{tabular}


Table 4 Results of ICP-MS analysis of food samples collected around Masaya in february-march 2012, reported in ppm dry weight

\begin{tabular}{|c|c|c|c|c|c|c|c|c|c|c|c|c|c|}
\hline & Al & $\mathrm{Cr}$ & $\mathrm{Fe}$ & Co & $\mathrm{Ni}$ & $\mathrm{Cu}$ & $\mathrm{Zn}$ & As & Se & $C d$ & Sn & $\mathrm{Hg}$ & $\mathrm{Pb}$ \\
\hline Banana & 4.19 & 1.61 & 18.5 & 0.01 & 0.21 & 2.91 & 4.99 & 0.01 & 0.04 & $<L L D$ & 0.01 & $<\mathrm{LLD}$ & 0.03 \\
\hline Banana & 3.17 & 0.01 & 15.5 & 0.00 & 0.09 & 5.72 & 8.01 & 0.01 & 0.05 & $<L L D$ & 0.01 & 0.02 & 0.04 \\
\hline Banana & 18.0 & 0.04 & 31.4 & 0.02 & 0.05 & 1.75 & 4.25 & 0.01 & 0.01 & $<\mathrm{LLD}$ & 0.05 & 0.01 & 0.10 \\
\hline Banana & 11.6 & 0.08 & 20.9 & 0.01 & 0.13 & 2.43 & 5.12 & 0.01 & 0.17 & $<\mathrm{LLD}$ & 0.01 & 0.04 & 0.06 \\
\hline Banana & 5.93 & 0.02 & 17.4 & 0.00 & 0.07 & 4.13 & 6.00 & 0.02 & 0.05 & $<\mathrm{LLD}$ & 0.01 & 0.02 & 0.05 \\
\hline Banana & 5.43 & 0.18 & 12.1 & 0.00 & 0.22 & 3.21 & 3.88 & 0.01 & 0.02 & $<\mathrm{LLD}$ & 0.02 & 0.09 & 0.06 \\
\hline Banana & 6.02 & 0.06 & 12.2 & 0.00 & 0.04 & 1.84 & 4.08 & 0.01 & 0.05 & $<\mathrm{LLD}$ & 0.01 & 0.04 & 0.06 \\
\hline Banana & 7.40 & 0.34 & 16.5 & 0.01 & 0.35 & 2.96 & 4.29 & 0.01 & 0.04 & $<\mathrm{LLD}$ & 0.01 & 0.13 & 0.06 \\
\hline Banana & 13.3 & 0.02 & 30.6 & 0.01 & 0.05 & 4.69 & 15.4 & 0.02 & 0.15 & $<\mathrm{LLD}$ & 0.02 & 0.08 & 0.09 \\
\hline Banana & 12.8 & 0.05 & 35.2 & 0.01 & 0.08 & 7.86 & 31.9 & 0.01 & 0.29 & $<L L D$ & 0.03 & 0.03 & 0.08 \\
\hline Banana & 19.5 & 0.02 & 31.0 & 0.01 & 0.04 & 3.08 & 5.85 & 0.00 & 0.02 & $<L L D$ & 0.01 & 0.02 & 0.10 \\
\hline Banana & 5.94 & 0.16 & 17.4 & 0.01 & 0.19 & 3.05 & 5.86 & 0.01 & 0.02 & $<L L D$ & 0.02 & 0.07 & 0.05 \\
\hline Mango & 26.6 & 0.07 & 40.5 & 0.02 & 0.06 & 3.77 & 4.23 & 0.01 & 0.10 & $<\mathrm{LLD}$ & 0.04 & 0.03 & 0.88 \\
\hline Pineapple & 47.2 & 0.06 & 68.6 & 0.06 & 0.24 & 7.09 & 11.4 & 0.02 & 0.04 & $<\mathrm{LLD}$ & 0.04 & 0.08 & 0.19 \\
\hline Pineapple & 38.3 & 0.04 & 75.3 & 0.17 & 1.61 & 15.3 & 21.0 & 0.05 & 0.08 & $<\mathrm{LLD}$ & 0.01 & 0.04 & 0.10 \\
\hline Pineapple & 43.0 & 0.10 & 67.4 & 0.04 & 0.26 & 10.6 & 15.0 & 0.02 & 0.03 & $<\mathrm{LLD}$ & 0.03 & 0.04 & 0.31 \\
\hline Pineapple & 86.6 & 0.20 & 138 & 0.08 & 0.34 & 6.40 & 14.4 & 0.03 & 0.02 & $<\mathrm{LLD}$ & 0.02 & 0.03 & 0.52 \\
\hline Pitaya plant & 87.7 & 0.02 & 27.9 & 0.47 & 0.25 & 4.21 & 23.3 & 0.02 & 0.03 & 0.09 & 0.00 & 0.09 & 0.07 \\
\hline Pitaya plant & 28.1 & 0.03 & 43.9 & 0.07 & 0.17 & 3.46 & 13.2 & 0.06 & 0.01 & $<\mathrm{LLD}$ & 0.01 & 0.01 & 0.16 \\
\hline Pitaya plant & 90.1 & 0.63 & 80.4 & 0.71 & 1.90 & 4.16 & 27.4 & 0.05 & 0.08 & $<\mathrm{LLD}$ & 0.04 & 0.05 & 0.17 \\
\hline Plantain & 4.44 & 0.12 & 14.7 & 0.00 & 0.19 & 2.94 & 4.63 & 0.00 & 0.08 & $<\mathrm{LLD}$ & 0.01 & 0.06 & 0.06 \\
\hline Plantain & 6.95 & 0.01 & 16.6 & 0.01 & 0.06 & 3.28 & 5.50 & 0.01 & 0.02 & $<\mathrm{LLD}$ & 0.01 & 0.03 & 0.14 \\
\hline Plantain & 8.19 & 0.01 & 18.9 & 0.01 & 0.02 & 2.88 & 3.30 & 0.01 & 0.01 & $<\mathrm{LLD}$ & 0.02 & 0.02 & 0.05 \\
\hline Plantain & 2.13 & 0.01 & 9.95 & 0.00 & 0.04 & 1.90 & 2.87 & 0.00 & 0.05 & $<\mathrm{LLD}$ & 0.00 & 0.03 & 0.02 \\
\hline Plantain & 10.8 & 0.01 & 23.1 & 0.01 & 0.03 & 3.08 & 5.34 & 0.01 & 0.01 & $<\mathrm{LLD}$ & 0.01 & 0.01 & 0.06 \\
\hline Quequisque & 6.77 & 0.02 & 20.6 & 0.19 & 0.17 & 13.7 & 17.3 & 0.01 & 0.03 & $<\mathrm{LLD}$ & 0.02 & 0.05 & 0.02 \\
\hline Quequisque & 4.83 & 0.02 & 24.6 & 0.12 & 0.22 & 13.1 & 14.9 & 0.03 & 0.08 & $<L L D$ & 0.06 & 0.10 & 0.03 \\
\hline Quequisque & 4.44 & 0.01 & 18.0 & 0.07 & 0.09 & 8.16 & 16.1 & 0.02 & 0.07 & $<L L D$ & 0.00 & 0.03 & 0.03 \\
\hline Spinach & 335 & 0.22 & 496 & 0.34 & 0.29 & 7.35 & 32.6 & 0.21 & 0.04 & 0.18 & 0.02 & 0.11 & 1.69 \\
\hline
\end{tabular}

LLD $=$ Lower limit of detection.

of explosion, because [the vent] is open. When the gases are free, they can escape. That prevents an explosion. [4, San Marcos]" Equally salient is the explosion hazard, also referred to as "flying/throwing stones [2, El Panama; 14, La Concha area; 36, La Concha area; 37, La Concha area]" again mentioned by 22 individuals, with 14 of those also having mentioned the gas hazard. A further 15 individuals mentioned volcanic ash and only 4 mentioned lava. Other hazards mentioned, included earthquakes (7 participants) and 5 or less participants named landslides and meteorological factors such as wind, cold, heavy rain and flooding.

At least 25 participants recognised spatio-temporal variations in the hazards posed by Masaya, particularly with respect to the area most affected and (recent) changes in activity. The six participants who explicitly named the worst affected areas identified them as 'la Concha' and 'El Crucero' (Figure 1). The presence of rain or wet conditions, including at the start of the rainy season (generally in April-May), intensified the salience of the gas hazard. One participant also reported being more aware of it on calm nights, whereas another reported feeling it more during windy conditions. Four participants, who themselves or their family had lived in the area all their lives, recalled the degassing crisis of the early 1980s, which was followed by a decrease in activity and a subsequent resurgence in the mid 1990s. In addition 11 participants mentioned that 

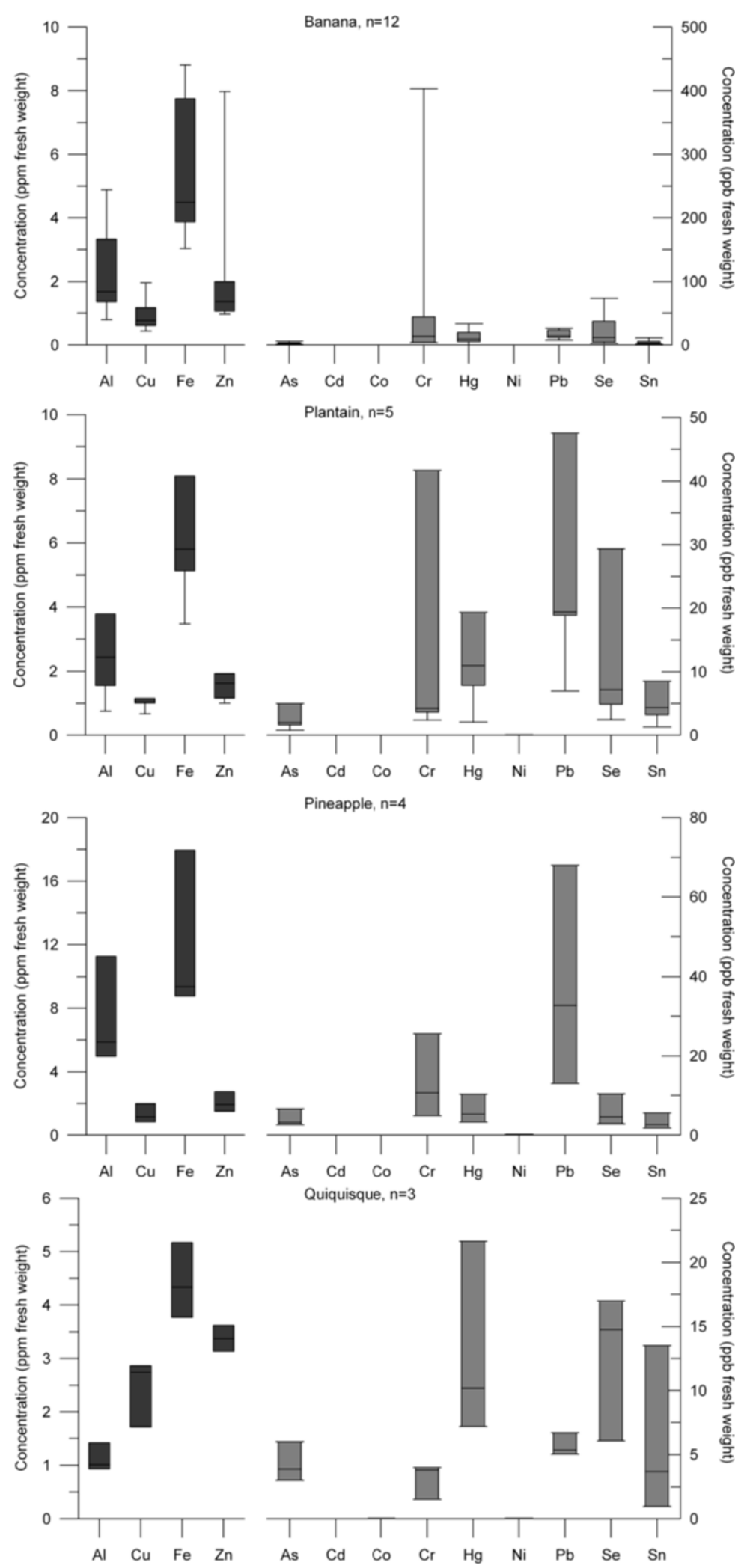

Figure 3 Heavy metal concentrations in selected food samples collected around Masaya volcano February-March 2012. 


\section{A}
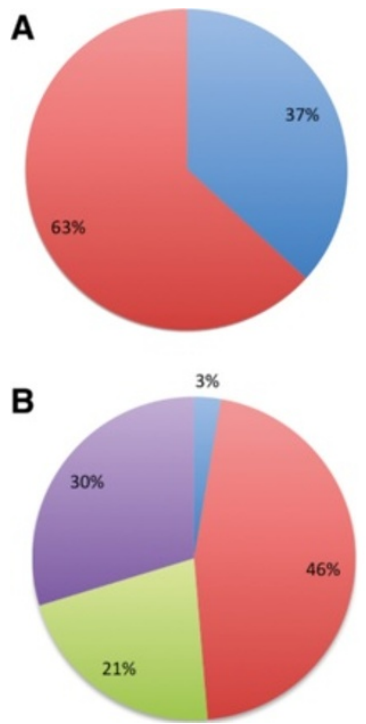
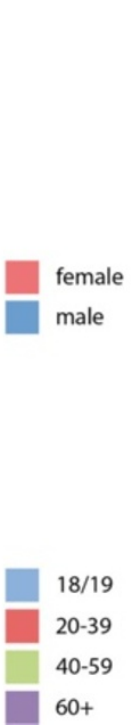

C

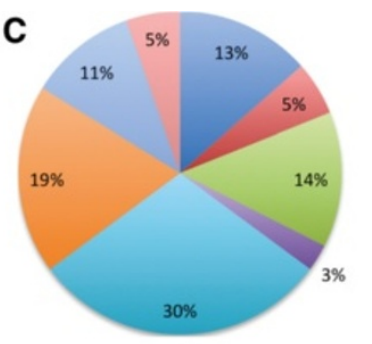

D

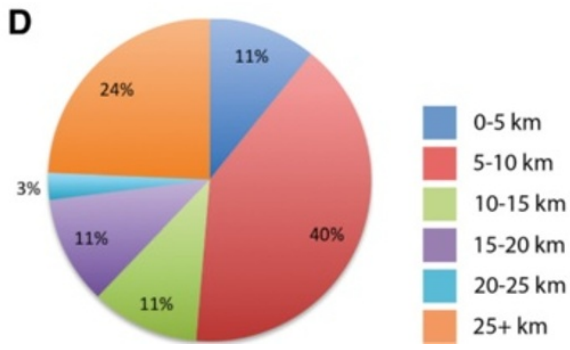

Figure 4 Basic demographics data of interview participants. (A) Sex. (B) Age. Exact age data were only collected if the individual appeared to be under the age of 30. (C) Occupation. (D) Distance from active vent.

the level of degassing has decreased in the past few years. As a result there are "(...) changes in the community after it has been turned off. Yes, more homes are being built. [37, La Concha area]" In addition "There are plants now, that before didn't produce much fruit. (...) it was known that on the hill avocados and citrus could not exist. But now they do exist. [16, Santa Terasita]" Coffee is also being planted in the area again. However, for those able to recall temporal changes in activity, the biggest hazard identified was “(...) that it will come to life again and affect the area as before [37, La Concha area]".

\section{Impacts}

\section{Personal impacts}

"I truly feel that we are definitely affected [34, El Panama]"

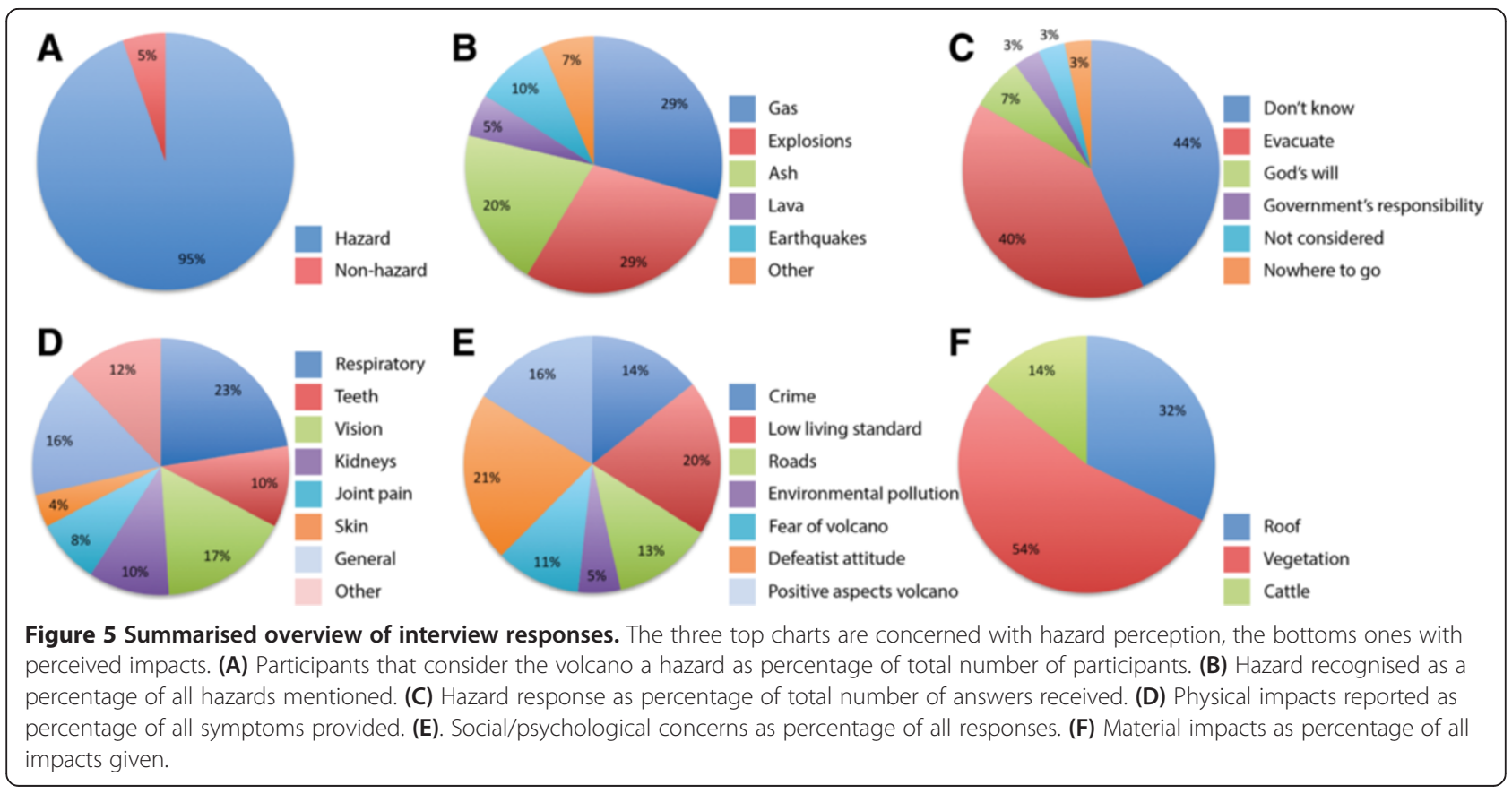


Personal impacts can be divided into physical and emotional impacts. The former were expressed directly by 30 participants whereas the latter were deduced directly or indirectly from conversations.

Physical symptoms attributed to the volcanic degassing were: burning of the skin, burning of the eyes, a burning sensation in the throat, respiratory problems, teeth staining, kidney problems, joint pain, a heart problem and tumours. The burning sensation of the eyes was described by one participant as "as though I had rubbed chilli in my eyes [29, along the road between El Crucero and Las Esquinas]". People also experienced increased susceptibility to cold and flu and children were identified as particularly vulnerable to respiratory conditions. Some participants also indicated that they realised the volcano was detrimental to their health but did not specify how. Areas where the most common physical symptoms were reported are roughly identified in Figure 6.

Social problems in the area appeared to be greater emotional stress factors than the volcano, with 21 participants mentioning a range of social issues, from crime (related to drugs, alcohol) to dangerous road conditions and anthropogenic environmental pollution. In addition, eleven participants conveyed problems resulting from basic human needs, such as clean drinking water, not being met. Specific volcano-induced stress was revealed directly by six participants who explicitly expressed fear of the volcano. Eleven participants displayed a defeatist attitude towards the volcano and its activity through statements such as "I can not do anything [31, along the road between El Crucero and Las Esquinas]", "it is what it is [32, Las Esquinas]" and "This volcano only causes problems. We would like to leave here forever (...) [34, El Panama]". Conversely, nine participants were able to identify positive aspects of the volcanic activity, which were related to tourism, "The only [good] thing would be that sometimes there is a tour guide that belongs to a community [26, Temoa]", education "It is a natural laboratory (...) So I think that it is good because taking students to the area, it pervades the theory with practice [5, Masatepe]" or agriculture, "The pineapple is the only thing not damaged by the volcano [13, La Concha area]".

\section{Material impacts}

"It affects all that is growing, the roofs of the houses. Therefore it destroys everything, it eats it, it damages everything. Yes, and the community as well. [32, La Esquinas]"

The most frequently reported damage resulting from volcanic activity (Figure 7) is damage to roofs (mentioned by half of the participants) and agriculture (30 participants). Directly downwind of Masaya roofs, generally made of metal (zinc, iron and tin were reported), have to be painted or replaced every 6 months to a year as they corrode. The maintenance frequency decreases with distance from the volcanic vent. Although less easily corroded roofing options are available, these are beyond the financial means of those who require them. Three participants also mentioned damage to walls.

Damage to crops and inability to grow certain species was reported by 30 of the 37 participants. Damage to crops was described as burns, and at close proximity to the vent the gases turn plants yellow and stunt growth. The affected crops are avocados, bananas (Musa sp.), beans, citrus, coffee, corn, mango and papaya. However, pineapple, pitaya, quiquisque and cabbage were reported to thrive. A fifth of participants also mentioned impacts on livestock and animals. Most commonly effects included swelling, trouble walking (also termed arthritis) or death and these were attributed to eating "poisoned [9, La Concha area]" grass.

\section{Hazard mitigation and risk reduction}

\section{"One tries to live with where you are [5, Masatepe]"}

The interviews revealed a desire for up-to-date factual information, "To know if it is dangerous a little communication from the people who do the monitoring is required, you have to advise the population of its behaviour. So I guess I must have a [hazard] map (...) [5, Masatepe]”. The need for information was re-iterated through direct statements such as "Well, that's where we need the voice of the scientist, to guide us [18, El Salto]" or indirectly as participants recalled things they had heard about the volcano but could not confirm whether these were true or current: "Not long ago I heard that it was covered and it was dangerous, but I do not know if that is or is not true. (...) [5, Masatepe]". At least a third of the participants said they rely on physical observations to know what the level of activity is, while six participants did not know how to tell if activity reached dangerous levels. Following on from this eight participants explicitly stated they did not know what to do if the volcano were to become dangerous, resulting in a circular argument: "Well, in case of danger, I would not do anything because we will not know when it is dangerous. [15, La Concha area]". One participant stated they had not considered the possibility of activity reaching dangerous levels. In the case of a volcanic emergency, which all of the respondents assumed would be related to explosive and/or extrusive activity rather than a degassing crisis, two of the respondents placed their fate in the hands of God and another expects the government to get them out of the area. Two participants said they had not been told what to do, while another three stated that only scientists would know what to do. Twelve of the participants stated 

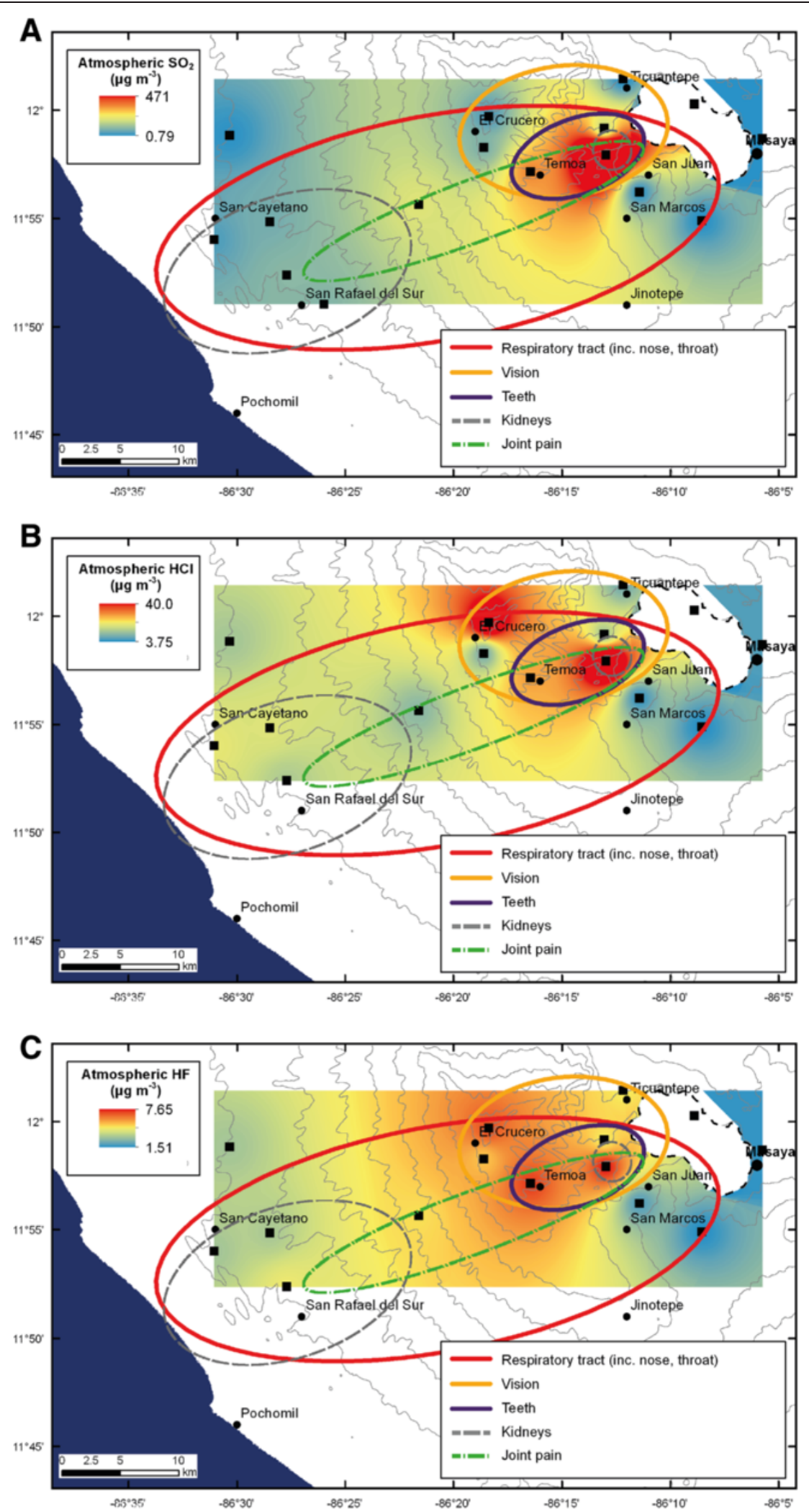

Figure 6 Physical symptoms as reported by study participants. Data overlain on ambient (A) $\mathrm{SO}_{2}$ (B) $\mathrm{HCl}$ and (C) $\mathrm{HF}$ concentrations in $\mu \mathrm{g} \mathrm{m}{ }^{-3}$ measured during the study period in February-March 2012. Surfaces interpolated from point measurements using IDW. Areas of increased self-reported prevalence of respiratory disease, eye irritation and teeth staining correspond to increased levels of volcanogenic gases. 


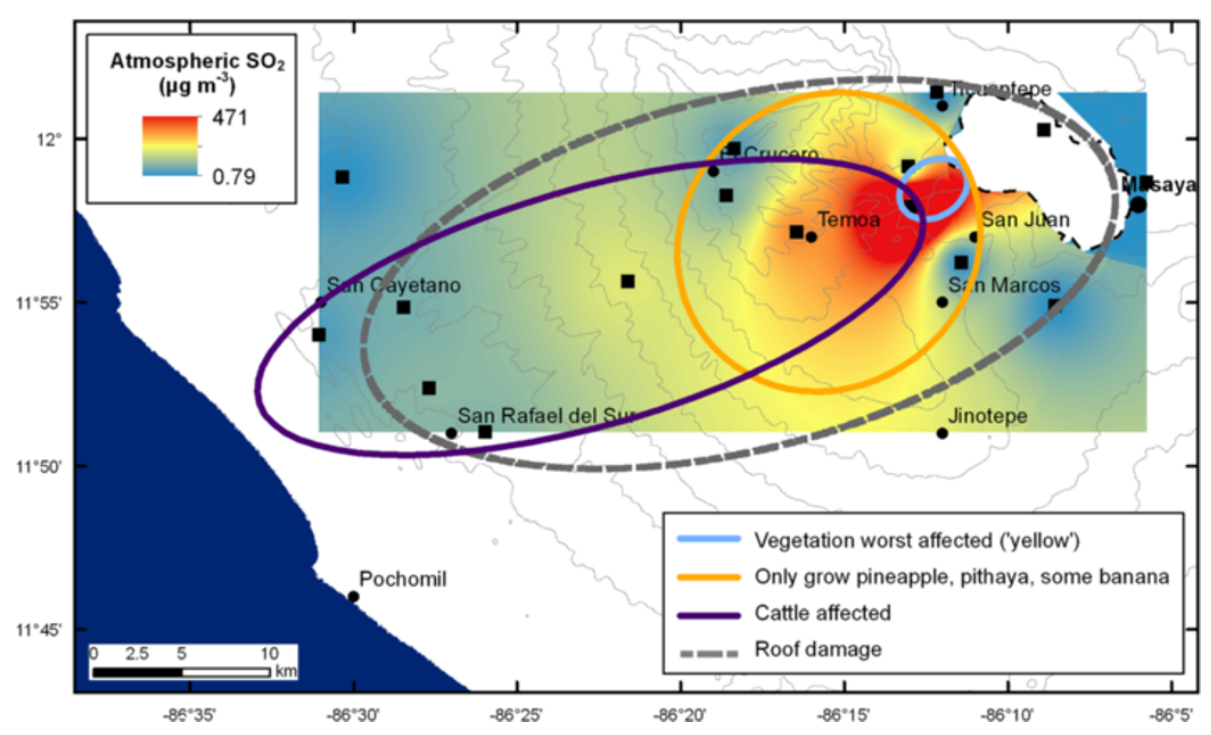

Figure 7 Material damage as reported by study participants. Data overlain on ambient $\mathrm{SO}_{2}$ concentrations in $\mu \mathrm{g} \mathrm{m}{ }^{-3}$ measured during the study period in February-March 2012. Surfaces interpolated from point measurements using IDW. Areas where vegetation was reported to be most affected correspond to elevated levels of $\mathrm{SO}_{2}$.

they would evacuate, with half of them going to areas of higher ground. One participant stated they had nowhere to go. Only two participants knew of the existence of the nationally coordinated responses to [volcanic] disasters, with one mentioning SINAPRED and the other Civil Defence (part of SINAPRED), though the latter added "There is little guidance on volcanic problems [18, El Salto]". There was also a single mention of a local search and rescue initiative. In response to the gas hazard only one participant mentioned they stay inside and the children are not allowed to leave the house.

Despite the apparent lack of factual information and prevalence of pessimistic views towards the volcano local communities have established, through empirical observation, an intrinsic way to mitigate the gas hazard: only crops that are better able to withstand the local environmental conditions (e.g. increased atmospheric $\mathrm{SO}_{2}$ and acid gas deposition), mainly pineapple and pitaya, are cultivated downwind of the active vent "Only pineapple and pitaya are grown. [...] Pineapple and pitaya withstand the acid. [10, La Concha area]" In fact, the $\mathrm{SO}_{2}$ emitted by Masaya is seen as making a positive contribution to pineapple cultivation, "The input from the volcano helps to protect [the crop] and produces a better quality pineapple. [15, La Concha area]" Based on the interviews conducted no other mitigation strategies are currently actively utilised around Masaya.

\section{Discussion}

"Only God can save us from the volcano [27, Las Nubes]"?
Nicaragua is ranked $26^{\text {th }}$ in the GFDRR (Global Facility for Disaster Reduction and Recovery) list of countries at high economic risk from multiple hazards (GFDRR 2010b), whose report also states that "Nicaragua is considered a leader in Central America because of its legal framework that enables a comprehensive and multi-sectoral approach to disaster risk management". Despite this, the fact that risk management is officially on the basic and adult education curriculum (Selby and Kagawa 2012) and Nicaragua's freely available full suite of hazard response plans (http:// siger.sinapred.gob.ni/), there is an apparent divide between government and local communities seemingly resulting from a disconnect in communication: irrespective of the high salience of the hazard(s) posed by Masaya there is little knowledge at the community level regarding hazard response and mitigation. This disconnect is not unique, the same gap has been identified in a 2009 survey of 7000 people in 48 countries (GNCSODR 2009), which raises the important question of how this could potentially be addressed.

\section{Hazards}

The gas hazard is a highly salient threat in communities surrounding Masaya volcano and this study quantitatively reiterates the direct physical hazard posed by the volcanic gases to human health, previously noted by Baxter et al. (1982) and Delmelle et al. (2002). Conversely, there is no indication of a potential indirect effect on health via the food chain: based on the analyses of crop samples the concentration of heavy metals is below maximum and guideline measurements for contaminants in foods as established by the joint FAO and 
WHO CODEX Alimentarius Commission (1995). However, total dietary intake of these heavy metals is not just restricted to the crops sampled here or the intake quantities used here but also includes other foods and drinks. Until a detailed dietary study is conducted in this area, the exact risk to of consuming crops grown in the area affected by the plume can not be accurately estimated.

\section{Perceived personal impacts}

The elevated level of salience of this invisible hazard clearly derives from the highly perceptible impacts of the degassing, in terms of individual, societal and material impacts. Many of the physical symptoms such as burning of the skin and eyes, nose and throat irritation and difficulty breathing, reported can be caused by exposure to elevated levels of $\mathrm{SO}_{2}$ (Longo 2009; Longo et al. 2005; Longo et al. 2008) and other volcanic gases (Ostro et al. 1991; Weinstein and Cook 2005). Although levels of $\mathrm{HCl}$ and $\mathrm{HF}$ measured here did not exceed WHO guidelines, local populations are likely to be exposed to levels greater than those reported by this study as diffusion tubes provide an average over the duration of exposure, which will include variations in degassing and wind direction. It should also be noted that atmospheric pollutants such as those from volcanic emissions, are encountered as mixtures in which effects of a single gas such as $\mathrm{SO}_{2}$, even when present at sub-threshold levels, can be intensified by other gases (Johns and Linn 2011). In addition, a large proportion of the gas hazard derives from particulate matter (PM; suspended solid and liquid droplets composed of acids and organic and inorganic components such as metals and dust). Particles less than $10 \mu \mathrm{m}$ in diameter are considered hazardous and volcanic PM is likely to have diameters less than $2.5 \mu \mathrm{m}$, increasing the potential for adverse health effects (e.g. Longo et al. 2008; Longo et al. 2010).

The teeth staining mentioned by participants appears to be confined to areas just downwind of the active vent. Teeth staining may indicate dental fluorosis, a preventable condition linked to ingestion of fluoride-rich drinking water during the tooth development stage (up to around 6-7 years of age). Although the majority of the area investigated utilises water deliveries rather than ground- or rainwater, one participant did indicate that rain water used to be collected in barrels and this may still be occurring in certain areas (SINAPRED 2009). Drinking of collected rainwater is a known aetiology for dental fluorosis (Allibone et al. 2012) and Delmelle et al. (2002) found levels of fluoride exceeding WHO guidelines at two locations where they collected rain water from roof catchments. Alternatively, teeth staining might be attributable to extrinsic staining from ferric or ferrous sulphide (e.g. Reid et al. 1977; Tirth et al. 2009; Ertugrul et al. 2003) formed in a reaction between $\mathrm{Fe}$ in the saliva or gingival exudate and $\mathrm{H}_{2} \mathrm{~S}$ or $\mathrm{H}_{2} \mathrm{SO}_{4}$. As $\mathrm{H}_{2} \mathrm{~S}$ is an insignificant component of Masaya's degassing (de Moor et al. 2013), $\mathrm{H}_{2} \mathrm{SO}_{4}$ formed when $\mathrm{SO}_{2}$ comes into contact with moist membranes is a more likely aetiology at Masaya. Mention of kidney disease was mostly found in lower elevation areas towards the coast, away from the summit of Masaya. It is therefore unlikely that the kidney disease mentioned is related to the volcanic activity. There is a high prevalence of Chronic Kidney Disease (CKD) in Nicaragua, specifically at lower elevations where the main occupations are related to agriculture and mining (Ramirez-Rubio et al. 2013; Weiner et al. 2013).

Stress related to social issues is of much greater concern to most participants than uncertainty surrounding the volcanic activity. However, cultural factors may have played a role in the low number of participants expressing emotional stress resulting from their proximity to Masaya. Indirect references to stress originating from the volcano came through mention of coping mechanisms such as adaptation, avoidance, denial and religion.

\section{Environmental impacts}

Damage to materials is due to the electrochemical effects, which are accelerated by environmental conditions (e.g. acid rain (Johnson and Parnell 1986) generated by the chemical composition of the volcanic plume as it interacts with the atmosphere. The same environmental conditions are also responsible for damage to vegetation (Johnson and Parnell 1986; Delmelle et al. 2002; Delmelle et al. 2001; McBirney 1956; Stoiber et al. 1986), in the form of leaf chlorosis and necrosis and decreased productivity. However, local communities have empirically determined that pineapples and pitaya are more resistant to the effects of the plume and are therefore preferentially growing these downwind of the vent. The decreased effect of $\mathrm{SO}_{2}$ on Ananas comosus is corroborated by experiments performed by Olszyk et al. (1987), which showed no effect of acute exposure to concentrations of $0.6-3$ ppm over 2-8 hour durations or chronic exposure to concentrations of $0.35-0.9 \mathrm{ppm}$ over $7-13$ days.

\section{Mitigation and risk management at the local level}

Risk is defined as the product of the probability of an event and its consequences (UNISDR 2009; Hood and Jones 1996). In the case of volcanic hazards, there is nothing that can be done to minimise the former so the focus is on reducing the effects. Negative consequences arise from the interplay between resilience (the capacity to adjust and recover from a hazard) and vulnerability (the susceptibility to damage from a hazard) (Paton 2005; UNISDR 2009). Despite the high salience of the gas hazard and recognition of other volcanic hazards few resilience factors were identified: only a single mitigation strategy is currently employed in the region. Combined with this there are multiple factors contributing to vulnerability around 
Masaya, these include lack of preparedness for (volcanic) hazards; issues of security and insufficient confidence in information provided by scientists and/or authorities; fatalistic attitudes towards risk reduction resulting from disproportionate perception of the risk of large scale and relatively low probability of occurrence acute hazards such as heavy ash fall, lava flows and pyroclastic surges; poverty; inequality; poor governance; and inadequate access to resources. In addition, the relative level of risk in the area is mounting as a result of the decrease in degassing during the past few years: the rising risk is due to increasing vulnerability as people are starting to grow different crops more susceptible to volcanogenic pollution and more homes are being built in the area suggesting an increase in population. An example of one of the crops now being grown is coffee: a crop previously grown and subsequently devastated directly downwind of Masaya (McBirney 1956). The promotion of coffee was reportedly promoted by a project although it was unclear who instigated this.

In light of Masaya's current and historical activity, characterised by cycles of chronic degassing of varying intensity, presently at a low point, increasing resilience should be prioritised. In addition, as natural disasters disproportionally affect poorer communities (e.g. Basher 2006), the contribution of persistent degassing to poverty, poor health and degradation of the local environment makes it a risk factor for acute hazards by increasing vulnerability in the area. Increasing resilience could occur through the identification and implementation of additional mitigation measures and increased education and outreach regarding emergency response at the community level. Implementing preparedness and mitigation measures related to an invisible underlying risk factor in a time of relative low gas flux is complex and multifaceted, but is likely to contribute to increased resilience in the face of acute hazards. It is therefore in line with 'reduce underlying risk factors', one of the five priorities for action identified in the Hyogo framework (UNISDR 2005), whose goal is to substantially reduce disaster losses by 2015.

For disaster risk reduction measures to be adapted and adhered to critical factors are community involvement (e.g. Cronin et al. 2004; UNDP 2004; Mercer et al. 2010; Paton et al. 2008) and integrating (small) changes with existing behaviours (Brown 2009). To successfully reduce risk in the area a wide range of strategies will have to be employed (Paton et al. 2005), and integrating disaster risk reduction with everyday activities and livelihoods will require looking further than the traditional institutionally dictated remit of volcanology.

One way in which vulnerability around Masaya may be reduced is through cultivation of pineapple, pitaya and other crops more resistant to the volcanogenic pollution. Taking pineapple as an example, there is apparent scope to increase the revenue from this crop. The area, specifically the municipality of Ticuantepe, has been one of the largest producers of pineapple in Nicaragua since the mid 1960s (Rose 2006). In 2006 there were around 800 pineapple producers in the area, operating on individual or small cooperatives. The variety most widely grown in the area is the 'Monte Lirio', which is not well regarded on the international market but cheaper to grow. Rose (2006) explored the pineapple cultivation from a purely economic perspective and concluded that if producers would convert to the internationally popular 'Smooth Cayenne' a higher profit margin would be obtained, ultimately leading to a reduction in poverty in the region. Of course implementation does not necessarily follow the simple process outlined here and it will require additional support and services such as access to financial means and infrastructure (Rose 2006). In addition monoculture brings with it its own costs (social, environmental and economic) and benefits. The possibility of more people settling in the at-risk area as the result of economic benefit is another factor that should be carefully considered. Certainly more research is required prior to implementation of crop conversion strategies as risk reduction measures.

A way of increasing resilience might be by addressing the poor governance in the area. Currently local communities do not receive adequate resources from the authorities to develop their adaptive capacity. In contrast, in neighbouring Costa Rica the Comisión Nacional de Prevención de Riesgos y Atención de Emergencias (CNE; www.cne.go.cr) coordinates a network of 400 communitylevel, 100 municipal-level, and 6 regional-level emergency Management Committees (GFDRR 2010a). These committees are set-up to facilitate the integration and coordination of communities, public and private institutions, NGOs and civil society in disaster (risk) management. Although a disconnect between national and local levels remains visible in Costa Rica (van Manen 2014), there is greater awareness at the local level. Awareness however, does not automatically convert to intentions to prepare, nor do intentions necessarily evolve into actions (e.g. Boura 1998; Paton et al. 2003), a challenge that is universal (e.g. Kievik and Gutteling 2011). It can potentially be addressed through the tailoring of risk management strategies to local concerns and context through increased empowerment of communities and community development. However, this does require adequate on-going support, resources and expertise from authorities.

\section{Conclusions}

This study contributes to the growing body of interand cross-disciplinary work focussed on understanding socio-economic dimensions of disasters, and how this information can effectively be integrated into disaster risk management. Through the use of complementary quantitative and qualitative approaches this work confirms that 
persistent degassing from Masaya volcano continues to pose a chronic health and economic hazard to the area on individual and community levels. Although the gases themselves are invisible, their effects are easily observed and therefore salience of this specific hazard is high. Salience of other volcanogenic hazards such explosions are also high as a result of personal experience of collective memory. Future research at Masaya should include more detailed socio-economic and agronomy-oriented studies, which include data on land ownership. In addition, thorough surveys of dietary intake patterns and material damages would provide valuable additional data.

Despite high levels of hazard salience in the local communities there is a divide between action at the national and local levels, with insufficient risk management information finding its way from the national to the local level. In addition, there is little response to, or mitigation of, the gas hazard specifically, with the sole mitigation strategy identified by this research deriving from communitybased empirical observations. This shows there is large scope for improvement and implementation of (gas) mitigation strategies and disaster preparedness at the level of, and in collaboration with, communities. As there is no single solution, this can only be achieved through the deployment of a wide range of strategies, and could include local level disaster management committees who have the ability to coordinate and tailor strategies to the local situation. This will require the availability of adequate levels of financial, technical and human resources, but by addressing the chronic hazard posed by persistent volcanic degassing, although intricate at a time of relatively low gas flux, capacity and resilience to chronic and acute hazards is likely to improve.

\section{Competing interests}

The author declares that she has no competing interests.

\section{Acknowledgements \\ This work was funded by Society in Science - The Branco Weiss Fellowship, administered by the ETH Zürich. Thanks to Juan Amador, Richard Oram and Phillippa Bailey for providing additional information regarding kidney disease. Thomas Puschak, DMD, kindly advised on dental fluorosis. Beatriz Coira was kind enough to advise on any translation queries I had. Gracias a Sergio Rocha, without his help some of the diffusion tubes wouldn't have gone up or come down. J. Williams and H. Rymer commented on an early version of this manuscript. The author would like to extend special thanks to four anonymous reviewers whose constructive feedback significantly improved this manuscript.}

Received: 20 November 2013 Accepted: 18 May 2014

Published online: 10 June 2014

\section{References}

Allibone R, Cronin S, Charley D, Neall V, Stewart R, Oppenheimer C (2012) Dental fluorosis linked to degassing of Ambrym volcano, Vanuatu: a novel exposure pathway. Environ Geochem Health 34(2):155-170, 10.1007/s10653-010-9338-2 AMUNIC, AMUSCLAM (2010) Plan Ambiental Municipal de La Concepción 2010-2020. La Asociación de Municipios de Nicaragua (AMUNIC) and La Asociación de Municipios de la Subcuenca III de la Cuenca Sur del Lago de Managua (AMUSCLAM)
Basher R (2006) Global early warning systems for natural hazards: systematic and people-centred. Philosophical transactions of the royal society a: mathematical, physical and engineering sciences. 364(1845):2167-2182, 10.1098/rsta.2006.1819

Baxter PJ, Stoiber RE, Williams SN (1982) Volcanic gases and health: Masaya Volcano, Nicaragua. Lancet 2(8290):150-151

Bergin M (2011) NVivo 8 and consistency in data analysis: reflecting on the use of a qualitative data analysis program. Nurse Res 18(3):6-12

Bird DK (2009) The use of questionnaires for acquiring information on public perception of natural hazards and risk mitigation - a review of current knowledge and practice. Nat Hazards Earth System Sci 9(4):1307-1325

Boura J (1998) Community fireguard: creating partnerships with the community to minimise the impact of bushfire. Aust J Emerg Manage 13:59-64

Brown T (2009) Change by design. Harper Collins, New York

Cassell C, Symon G (1994) Qualitative research in work contexts. In: Cassell C, Symon $\mathrm{G}$ (eds) Qualitative methods in organizational research, a practical guide. Sage, London, pp 1-13

CATIE (1996) Mercadeo agricola en la zona Atlantica de Costa Rica. Centro Agronómico Tropical de Investigación y Enseñanza. Turrilaba, Costa Rica

Cronin SJ, Gaylord DR, Charley D, Alloway BV, Wallez S, Esau JW (2004) Participatory methods of incorporating scientific with traditional knowledge for volcanic hazard management on Ambae Island, Vanuatu. Bull Volcanol 66(7):652-668

D'Alessandro W (2006) Gas hazard: An often neglected natural risk in volcanic areas. In: Martin-Duque JF, Brebbia CA, Emmanouloudis DE, Mander U (eds) Geo-Environment and Landscape Evolution II, pp 369-378

de Moor JM, Fischer TP, Sharp ZD, King PL, Wilke M, Botcharnikov RE, Cottrell E, Zelenski M, Marty B, Klimm K, Rivard C, Ayalew D, Ramirez C, Kelley KA (2013) Sulfur degassing at Erta Ale (Ethiopia) and Masaya (Nicaragua) volcanoes: Implications for degassing processes and oxygen fugacities of basaltic systems. Geochem Geophys Geosyst 14(10):4076-4108, 10.1002/ggge.20255

DEFRA (2006) Guidelines for halogens and hydrogen halides in ambient air for protecting human health against acute irritancy effects. DEFRA Publications, London

DEFRA (2009) Addendum to Guidelines for Halogens and Hydrogen Halides in Ambient Air. DEFRA Publications, London

Delmelle P, Stix J, Bourque CPA, Baxter PJ, Garcia-Alvarez J, Barquero J (2001) Dry deposition and heavy acid loading in the vicinity of Masaya Volcano, a major sulfur and chlorine source in Nicaragua. Environ Sci Technol 35(7):1289-1293, 10.5555/es000153m

Delmelle P, Stix J, Baxter PJ, Garcia-Alvarez J, Barquero J (2002) Atmospheric dispersion, environmental effects and potential health hazard associated with the low-altitude gas plume of Masaya volcano, Nicaragua. Bull Volcanol 64(6):423-434, 10.1007/s00445-002-0221-6

DFID (2006) Reducing the Risk of Disasters -Helping to Achieve Sustainable Poverty Reduction in a Vulnerable World: A DFID policy paper

Donovan K (2010) Doing social volcanology: exploring volcanic culture in Indonesia. Area 42(1):117-126, 10.1111/j.1475-4762.2009.00899.x

Ertugrul F, Elbek-Cubukcu C, Sabah E, Mir S (2003) The oral health status of children undergoing hemodialysis treatment. Turk J Pediatr 45(2):108-113

FAO (2007) Guia de seguridad alimentaria y nutricional para uso del personal agropecuario de Nicaragua. FAO, Rome

Gaillard JC (2008) Alternative paradigms of volcanic risk perception: the case of Mt. Pinatubo in the Philippines. J Volcanol Geotherm Res 172(3-4):315-328, 10.1016/j.jvolgeores.2007.12.036

GFDRR (2010a) Disaster Risk Management in Central America: GFDRR Country Notes Costa Rica. Global Facility for Disaster Risk Reduction and Recovery, Washington DC

GFDRR (2010b) Disaster Risk Management in Central America: GFDRR Country Notes Nicaragua. Global Facility for Disaster Risk Reduction and Recovery, Washington DC

GNCSODR (2009) Clouds but little rain... Views from the Front Line. A local perspective of progress towards implementation of the Hyogo Framework for Action. Natural Hazards Observer. Global Network of Civil Society Organisations for Disaster Reduction

Gregg CE, Houghton BF, Johnston DM, Paton D, Swanson DA (2004) The perception of volcanic risk in Kona communities from Mauna Loa and HualfÅlai volcanoes, Hawai,Äui. J Volcanol Geotherm Res 130(3,Äi4):179-196, http://dx.doi.org/10.1016/S0377-0273(03)00288-9

Hansell A, Oppenheimer C (2004) Health hazards from volcanic gases: a systematic literature review. Arch Environ Health 59(12):628-639 
Haynes K, Barclay J, Pidgeon N (2008) Whose reality counts? Factors affecting the perception of volcanic risk. J Volcanol Geotherm Res 172(3-4):259-272, 10.1016/j.jvolgeores.2007.12.012

Hood C, Jones DKC (1996) Accident and design: contemporary debates in risk management. Routledge, Abingdon, UK

INETER (2008) Boletin Mensual Sismos y Volcanes de Nicaragua, Junio, 2008. INTER, Managua

INETER (2012) Boletin Mensual Sismos y Volcanes de Nicaragua, Mayo, 2012 INTER, Managua

Jaafar RA, Rahman ARBA, Mahmod NZC, Vasudevan R (2009) Proximate analysis of dragon fruit (hylecereus polyhizus). Am J Appl Sci 6(7):1341-1346

Johns DO, Linn WS (2011) A review of controlled human SO 2 exposure studies contributing to the US EPA integrated science assessment for sulfur oxides. Inhal Toxicol 23(1):33-43, 10.3109/08958378.2010.539290

Johnson N, Parnell RAJ (1986) Composition, distribution and neutralization of "acid rain" derived from Masaya volcano, Nicaragua. Tellus 38B:106-117

Kelman I, Mather TA (2008) Living with volcanoes: the sustainable livelihoods approach for volcano-related opportunities. J Volcanol Geotherm Res 172(3-4):189-198, 10.1016/j.jvolgeores.2007.12.007

Kievik M, Gutteling JM (2011) Yes, we can: motivate Dutch citizens to engage in self-protective behavior with regard to flood risks. Nat Haz 59(3):1475-1490, 10.1007/s11069-011-9845-1

Longo BM (2009) The Kilauea volcano adult health study. Nurs Res 58(1):23-31

Longo BM, Grunder A, Chuan R, Rossignol A (2005) SO(2) and fine aerosol dispersion from the Kilauea plume, Kau district, Hawaii, USA. Geology 33(3):217-220, 10.1130/g21167.1

Longo BM, Rossignol A, Green JB (2008) Cardiorespiratory health effects associated with sulphurous volcanic air pollution. Public Health 122(8):809-820, 10.1016/j.puhe.2007.09.017

Longo BM, Yang W, Green JB, Crosby FL, Crosby VL (2010) Acute health effects associated with exposure to volcanic air pollution (vog) from increased activity at Kilauea Volcano in 2008. J Toxicol Environmental Health-Part a-Current Issues 73(20):1370-1381

MARENA (2002) Norma Técnica Obligatoria Nicaragüense de Calidad del Aire. MARENA, Managua

McBirney AR (1956) The Nicaraguan volcano Masaya and its caldera. Trans Am Geophys Union 37(1):83-96

Mercer J, Kelman I, Taranis L, Suchet-Pearson S (2010) Framework for integrating indigenous and scientific knowledge for disaster risk reduction. Disasters 34(1):214-239, 10.1111/j.0361-3666.2009.01126.x

Mikkelsen BH (1995) Methods for Development Work and Research: A New Guide for Practitioners. Sage Publications, London

Nadeau PA, Williams-Jones G (2009) Apparent downwind depletion of volcanic $\mathrm{SO}(2)$ flux-lessons from Masaya Volcano, Nicaragua. Bull Volcanol 71(4):389-400, 10.1007/s00445-008-0251-9

Olszyk DM, Bytnerowicz A, Fox CA (1987) Sulfur dioxide effects on plants exhibiting Crassulacean acid metabolism. Environmental Pollution 43(1):47-62, http://dx.doi.org/10.1016/0269-7491(87)90167-9

Ostro BD, Lipsett MJ, Wiener MB, Selner JC (1991) Asthmatic responses to airborne acid aerosols. Am J Public Health 81(6):694-702

Parnell RAJ (1986) Soil Sci 42:43-55

Paton D (2005) Community resilience: integrating hazard management and community engagement. Paper presented at the Engaging Communities. Brisbane, Australia

Paton D, Violanti JM, Smith LM (2003) Promoting Capabilities to Manage Postraumatic Stress: Perspectives on Resilience. Charles C Thomas, Springfield, Illinois

Paton D, Smith L, Johnson D (2005) When good intentions turn bad: promoting natural hazard preparedness. Aust J Emergency Manage 20(1):25-30

Paton D, Smith L, Daly M, Johnston D (2008) Risk perception and volcanic hazard mitigation: Individual and social perspectives. J Volcanol Geotherm Res 172(3-4):179-188, 10.1016/j.jvolgeores.2007.12.026

Ramirez-Rubio O, McClean MD, Amador JJ, Brooks DR (2013) An epidemic of chronic kidney disease in Central America: an overview. J Epidemiol Community Health 67(1):1-3, 10.1136/jech-2012-201141

Reid JS, Beeley JA, MacDonald DG (1977) Investigations into black extrinsic tooth stain. J Dent Res 56(8):895-899

Ricci T, Barberi F, Davis MS, Isaia R, Nave R (2013) Volcanic risk perception in the Campi Flegrei area. J Volcanol Geotherm Res 254(0):118-130, http://dx.doi.org/10.1016/j.jvolgeores.2013.01.002

Ritchie J, Lewis J (2003) Qualitative research practice. Sage Publications, London
Rose SE (2006) El cultivo de piña en el municipio de Ticuantepe: Situación actual y perspectivas. Encuentro 74:69-79

Rymer H, de Vries BV, Stix J, Williams-Jones G (1998) Pit crater structure and processes governing persistent activity at Masaya Volcano, Nicaragua. Bull Volcanol 59(5):345-355, 10.1007/s004450050196

SAGARPA (2005) Plan rector del sistema producto mango. La Secretaría de Agricultura, Ganadería, Desarrollo Rural, Pesca y Alimentación

Selby D, Kagawa F (2012) Disaster risk reduction in school curricula: Case studies from thirty countries. United Nations Childrens Fund (UNICEF), Geneva, Switzerland

SINAPRED (2005) Reporte sobre las Amenazas, Vulnerabilidad y Riesgos ante Inundaciones, Deslizamientos, Actividad Volcánica y Sismos; Departemento Masaya, Municipio Masaya. SINAPRED, Managua

SINAPRED (2009) Plan de respuesta municipal; Municipio de Tincuantepe. Managua, SINAPRED, Managua

Smithsonian Institution (2001) Masaya. Bulletin of the Global Volcanism Network 26:04

Stoiber RE, Williams SN, Huebert BJ (1986) Sulfur and halogen gases at Masaya Caldera Complex, Nicaragua: Total flux and variations with time. J Geophysical Res: Solid Earth 91(B12):12215-12231, 10.1029/JB091iB12p12215

Tirth A, Srivastava BKS, Nagarajappa R, Pradeep Tangade P, Ravishankar TL (2009) An Investigation into Black Tooth Stain Among School Children in Chakkar Ka Milak of Moradabad City, India. J Oral Health Community Dent 3(2):34-37

UNDP (2004) Volcano risk reduction: A case study from Goma (DRC). Disaster Reduction Unit, United Nations Development Programme - Bureau for Crisis Prevention and Recovery

UNISDR (2005) Hyogo framework for action 2005-2014: Building the Resiience of Nations and Communities to Disasters. http://www.unisdr.org/we/ coordinate/hfa. Accessed January 282012

UNISDR (2009) UNISDR Terminology on Disaster Risk Reduction. United Nations International Strategy for Disaster Risk Reduction, Geneva, Switzerland, p. 35

USDA (2012) USDA National Nutrient Database for Standard Reference, Release 25. http://www.ars.usda.gov/ba/bhnrc/ndl

van Manen SM (2014) Hazard and risk perception at Turrialba volcano (Costa Rica); implications for disaster risk management Applied Geography. 10.1016/j.apgeog.2014.02.004

Viramonte JG, Incer-Barquero J (2008) Masaya, the "Mouth of Hell", Nicaragua: Volcanological interpretation of the myths, legends and anecdotes. J Volcanol Geotherm Res 176(3):419-426, 10.1016/j.jvolgeores.2008.01.038

Weiner DE, McClean MD, Kaufman JS, Brooks DR (2013) The Central American epidemic of CKD. Clin J Am Soc Nephrol 8(3):504-511, 10.2215/cjn.05050512

Weinstein P, Cook A (2005) Volcanic emissions and health. In: Selinus O (ed) Essentials of medical geology: Impact of the natural environment on public health. Academic Press Inc, Oxford, pp 203-226

WHO (2000) Guidelines for air quality. World Health Organization, Geneva, Switzerland

WHO (2006) WHO Air quality guidelines for particulate matter, ozone, nitrogen dioxide and sulfur dioxide; Global update 2005. World Health Organization, Geneva, Switzerland

WHO (2013) Ten chemicals of major public health concern. http://www.who.int/ ipcs/assessment/public_health/chemicals_phc/en/. Accessed March 172014

WHO, FAO (1995) CODEX general standard for contaminants and toxins in food and feed 193-1995. http://www.codexalimentarius.org/download/standards/ 17/CXS_193e.pdf. Accessed June 252013

Williams SN (1983) Geology and the eruptive mechanisms of Masaya Caldera Complex. Nicaragua, Dartmouth College, Hanover, New Hampshire, USA

doi:10.1186/s13617-014-0009-3

Cite this article as: van Manen: Perception of a chronic volcanic hazard: persistent degassing at Masaya volcano, Nicaragua. Journal of Applied Volcanology 2014 3:9. 